\title{
How to Present Ancient Theatre on Television
}

\section{Eva Stehlíková}

The three-part series from the $\mathrm{BBC}^{1}$ production on Greek theatre is more than interesting for us by what it says and how it says it. The script was written by Michael Scott, associate professor in Classics and Ancient History at the University of Warwick, who is well known both as an expert and as a very productive collaborator on documentaries for National Geographic, the History Channel, ITV and the BBC. ${ }^{2}$

Michael Scott remains the guide through all three episodes but he employs experts on ancient theatre to help him, beginning with probably the most famous of them, Oliver Taplin and ending with Gesina Manuwald, a scholar of Roman theatre. In a pleasant way, this enlarges the range of academics introduced to the viewer as well as the personal aspect of interpreting Greek theatre. For the most part, the academics are in complete agreement. Perhaps the only minor controversy occurs when the ever-emotional Edith Hall brands Creon in Antigone as the most incompetent leader - a statement decently opposed by Robin Osborne who points out the difficult situation in which Creon found himself (due to contradictory laws). It appears, therefore,

1 Ancient Greece The Greatest Show on Earth. BBC 2013, broadcast in the Czech Republic by Prima Zoom Television in 2017. Translating subtitles often entails difficulties because place names (as is the case with proper nouns) have different forms in different languages. Fortunately, in this case, it concerns only what is known in the Czech language as Tarent, for which the form Taras is used here. This form is, though, unknown to Czech viewers as it does not occur either in Czech popular or scholarly literature.

2 More information at: Michael Scott [online]. (C2018. Available online at: https://michaelscottweb.com/ that Michael Scott interprets the development of Greek theatre and drama in a way that roughly corresponds to the current interpretation shared across academia. On one occasion, though, a possibility of seeing things in a different way surfaces with Paul Cartledge admitting that he belongs to a certain group of scholars who see tragedy as a political tool.

With pleasant enthusiasm, Michael Scott tells the story of the Greek theatre in a refreshing and entertaining way. The first episode focuses on the emergence of the theatre in the sixth century $\mathrm{BC}$ and its strong links with the development of Athenian democracy in the fifth century. The second episode covers roughly the period from the end of the Peloponnesian War when Athens gradually loses its status as well as its democracy. During the reign of Philip of Macedon, his son Alexander and heirs of his Empire, there occurs a fundamental shift in society and theatre. The third episode focuses on ancient Rome. Understandably, there is no place for details, and we can only admire that Michael Scott has managed to guide viewers through a long time and enormous space without resorting to oversimplification. ${ }^{3}$ This is true especially about the first and second episodes. However, I admit I find the third episode somewhat problematic. From a very complicated process, only those moments have been highlighted (logically

3 I omit minor issues such as the claim that no Satyr plays have been preserved (what about the Cyclops or a major piece of the Ichneutae?) or too simplified an interpretation of Euripides' Bacchae, which simply served as a spectacular introduction to the second episode of the series. 
in view of the chosen point of departure) which connect Roman with Greek theatre. Rome is understood here as a mere preserver and mediator of the legacy of Greek theatre. This fact is certainly beyond dispute. The Romans, however, opened a new stage of cultural development to the world precisely by being able to accept a foreign cultural heritage (not just Greek but also such genres as Oscan Atellana and international mime) adapting and reshaping them after their own heart. ${ }^{4}$ I find it just as difficult as accepting a simplified interpretation of Plautus' comedy presented here. Though Menander's name is mentioned here and two of his comedies are discussed, Plautus' comedy is not so much compared with Menander as with Aristophanes' comedies. Perhaps this is to make more visible the difference between the comedy flourishing at the time of Greek democracy and comedy of other eras. This, however, prevents the very nature of the Roman vis comica to shine through and its ability to create a distinctive environment fairly referred to as Plautinopolis. In short: it seems that this episode suffers from a kind of Winckelmannian disdainfulness...

Interpretation is, however, only one component of a television account. Image is just as important. Television can benefit from the fact that it can combine interpretation with documents and embed narrative into places associated with ancient culture, history and theatre. While often doing this, it achieves big effects in some places. The effect is also bolstered by employing embedded acting scenes along the lines of popular action movies. But the most promising op-

4 Another interesting genre, ancient pantomime, is dealt with in a rather confusing way. Was it really a Roman invention? Did it exist from the beginning of the Roman theatre? portunity here is to look at various sites in which Greek theatres have been preserved. Unfortunately, I see a problem here. The television production has taken to intertwining narration mainly by placing the narrator in the 'photogenic' theatre in Epidaurus regardless of what is currently discussed. We can, however painfully, ignore the fact that the theatre in Epidaurus was not built until the last third of the fourth century, so strictly speaking it should have no place in the first episode at all. In the same vein it is difficult to see when during a discussion about the theatre in Syracuse, an image of the current state of the theatre blends in a totally illogical fashion with a view of the koilon of the theatre in Epidaurus. The theatre in Dodona is treated in a similar arbitrary way in the first episode of the series and so on. I do not attribute these absurd camera travels across Greece to Michael Scott. Indeed, that would be completely inappropriate because he himself specializes in the spatial experience of Greek and Roman societies and landscapes (SCOTT 2010, 2013). The aesthetics of television is simply ruled by the image.

Some problems probably follow from the fact that it was necessary to distribute facts across three episodes of the show. So, it happened that in the beginning we learn what the theatre in Thorikos (and indeed in Rhamnous) looked like but only in the second episode there is a mention of the story of the Theatre of Dionysus. It is only then that we find out that the theatre looked entirely different at the time of the three major tragic playwrights and that its current appearance originates in later reconstructions. In contrast, the development of the Greek and Roman theatre space (albeit somewhat simplified) is factual and provides the viewer with a clear picture. Making history and 
building development present on television is actually a fairly simple thing. Nevertheless, presenting theatre, i.e. drama and its production, is much more complicated indeed.

The path of least resistance is chosen here: drama is retold using a simple animated film. But what about production? Theatre only exists when it takes place. Even a video of a production cannot help. There another author entity is added that thanks to its ability to alternate between the whole and details, presents the production in a form in which it has never existed on stage. And what about the production of plays in times so remote from us as ancient theatre? Television bypasses this difficulty by presenting contemporary materials - posters, photographs, clips from Cacoyannis' film The Trojan Women and clips from recordings of modern productions. This would not matter, of course, if at least from time to time there was presented an explanation that this is what we imagine a production to be right now and that we can hardly base our perception on this production to see what it was in ancient times. Although there are relatively few documents related to the earliest stage of the ancient theatre, it seems that some of them could be used though. For instance, when the Pronomos vase is presented here, it would be worth pointing out the masks depicted on it. Otherwise, the viewer might think that all Greek theatre looked like Peter Hall's famous Oresteia, ${ }^{5}$ with all due respect to this artistic performance.

5 Peter Hall's 1981 Oresteia, the product of six months of research and rehearsal, ran for 65 sell-out performances at the Olivier Theatre, London, and was broadcast by Channel Four in 1982. As at Epidaurus in $458 \mathrm{BC}$, male and female roles were played by men, all of whom were masked.
Great admiration, which the show has received, goes in particular to Michael Scott, whose interpretation of the story of Greek theatre in a pleasant way exceeds the ordinary accumulation of known facts while giving it a seal of individuality. In contrast, the television machine (probably everywhere in the world) still uses the same stereotypes revealing that the liking of images is more important for it than the accuracy and detail of the communication itself.

\section{Bibliography}

SCOTT, Michael, 2010. Delphi and Olympia: The Spatial Politics of Panhellenism in the Archaic and Classical Periods. Cambridge/New York: Cambridge University Press, 2010. SCOTT, Michael. 2013. Space and Society in the Greek and Roman Worlds. Cambridge/New York: Cambridge University Press, 2013. 